\title{
Expression of microRNA-222 in serum of patients with Alzheimer's disease
}

\author{
QINGHONG ZENG ${ }^{1 *}$, LINQING ZOU ${ }^{2 *}$, LI QIAN $^{3}$, FANG ZHOU $^{1}$, HONGXIA NIE ${ }^{1}$, SHANHUA YU ${ }^{1}$, \\ JIANDONG JIANG $^{1}$, AIXIA ZHUANG ${ }^{1}$, CHUANQI WANG $^{1}$ and HAOJIANG ZHANG ${ }^{1}$ \\ ${ }^{1}$ Department of Neurology, The Second People's Hospital of Lianyungang, Lianyungang, Jiangsu 222006; \\ ${ }^{2}$ Department of Human Anatomy, Jiangsu Key Laboratory of Neuroregeneration, Nantong University, Nantong, \\ Jiangsu 226019; ${ }^{3}$ Department of Clinical Laboratory, The Second People's Hospital of Lianyungang, \\ Lianyungang, Jiangsu 222006, P.R. China
}

Received April 14, 2016; Accepted March 24, 2017

DOI: $10.3892 / \mathrm{mmr} .2017 .7301$

\begin{abstract}
The aim of the present study was to determine the association between Alzheimer's disease (AD) and microRNA-222 in the serum of patients with AD. The expression of microRNAs was detected and the results were verified using microarray analysis and reverse transcription-quantitative polymerase chain reaction. The results indicated that there were 35 strips of microRNA in the mild AD group, in which the difference of expression signal was $>500 \mathrm{IU} / \mathrm{ml}$. There were 26 strips of microRNA with a difference in expression signal of $>500 \mathrm{IU} / \mathrm{ml}$ in the mild and moderate AD groups. The downregulation of microRNA-222 in the mild and moderate groups was statistically significant $(\mathrm{P}<0.01)$, and the expression of microRNA-222 in the moderate group was significantly lower, compared with that in the mild AD group $(\mathrm{P}<0.05)$. It was concluded that microRNA-222 may affect the occurrence and development of AD through a variety of mechanisms, and may serve as a biomarker for the early diagnosis of AD.
\end{abstract}

\section{Introduction}

Alzheimer's disease (AD) is a neurodegenerative disease, which is characterized by cognitive, language and memory disorders (1). AD is the leading cause of dementia in the elderly (2). The development and application of novel technology have

Correspondence to: Dr Qinghong Zeng, Department of Neurology, The Second People's Hospital of Lianyungang, 41 East Hailian Road, Xinpu, Lianyungang, Jiangsu 222006, P.R. China

E-mail: zengqlyg@sina.com

Dr Linqing Zou, Department of Human Anatomy, Jiangsu Key Laboratory of Neuroregeneration, Nantong University, 9 Qiangyuan Road, Nantong, Jiangsu 226019, P.R. China

E-mail: zoulqnt@sina.com

*Contributed equally

Key words: Alzheimer's disease, microRNAs, microRNA-222 enhanced investigations in proteomics. Matrix-assisted laser desorption ionization time of flight mass spectrometry (3), high performance liquid chromatography and inductively coupled plasma mass spectrometry (4), liquid chromatography ultraviolet spectrometry/mass spectrometry (5) and shotgun proteomics (6) are used for the separation, and qualitative and quantitative analyses of proteins, which together can contribute to the identification of novel biomarkers for AD; however, a single diagnostic method with high specificity and sensitivity remains to be elucidated.

MicroRNAs, with a length of 22 nucleotides in eukaryotes, are involved in the post-transcriptional regulation of non-encoding small RNA molecules. The primary function of microRNAs is to regulate gene expression by inhibiting the translation of target mRNAs or promoting the degradation of mRNAs (7), therefore, they are involved in cell cycle regulation and individual cycle development (8). In the nervous system, microRNAs regulate nerve cell proliferation, differentiation and apoptosis at different developmental stages and in different regions under physiologic conditions, and microRNAs are important in the formation of human cognition and memory $(9,10)$. Certain microRNAs are present in neurons in the form of polyribosome binding (11), which shows tissue and stage specificity for growth and development of the brain. There is stable expression of microRNAs in serum (12). This present study used Paraflo microfluidic chip technology for the detection of serum microRNAs in patients with AD and in healthy patients. Differences in microRNAs were detected using software, followed by reverse transcription-quantitative polymerase chain reaction analysis with fluorescence to verify the microRNA-222 results. The aim of the present study was to identify biomarkers for the early diagnosis of $\mathrm{AD}$.

\section{Patients and methods}

Study subjects. Inpatients and outpatients who were initially diagnosed with AD between October 2012 and June 2015 were recruited for the present study and were divided into two groups according to the severity of AD. There were 30 patients with mild AD and 30 patients with moderate AD. In addition, 30 healthy patients who had normal activity, no 
organic encephalopathy, no abnormal neurologic manifestations, and a mini-mental state examination (MMSE) score $\geq 28$ were included as the normal group. The Ethics Committee of the Second People's Hospital of Lianyungang (Nantong, China) approved the present study, and informed consent was obtained from participants.

The exclusion criteria for the present study were as follows: i) History of cerebral vascular disease; ii) traumatic brain injury; iii) toxic, metabolic or other brain disorders; iv) drug therapy prior to diagnosis; v) blood system disease; vi) dementia caused by vascular and other causes; and vii) no signed informed consent.

Diagnostic criteria. The diagnostic criteria for AD were based on the 2011 National Institute on Aging and the Alzheimer's Association (13). The dementia rating was based on MMSE and the AD assessment scale (14). The patients were divided according to the MMSE score into mild (15< MMSE $\leq 26)$ and moderate AD groups $(10 \leq \mathrm{MMSE} \leq 15)$. The criteria for dementia based on the MMSE score were as follows: Illiterate, $\leq 17$; elementary, $\leq 20$; middle school, $\leq 22$; and university, $\leq 24$.

Data collection. The sex, age, medical history (hypertension, diabetes and coronary heart disease), smoking history and alcohol consumption history, and the levels offibrin, homocysteine, C-reactive protein and lipids in the blood were recorded for all study subjects.

Sample collection. Venous blood samples were collected from the patients in the AD group prior to treatment. Venous blood samples were collected from patients in the normal group at the physical examination center of the Second People's Hospital of Lianyungang (Haizhou, China). The serum was extracted by centrifugation for $15 \mathrm{~min}$ at $14,000 \mathrm{x} \mathrm{g}$ and $4^{\circ} \mathrm{C}$ from venous blood, and stored at $-80^{\circ} \mathrm{C}$.

Total RNA extraction. The serum samples (100-200 $\mu$ l) stored in low-temperature refrigeration were collected, placed on ice to gently melt, and mixed well. TRIzol LS (Beijing Sciencbio Biotechnology Co., Ltd., Beijing, China) at a volume 3 times that of the sample was added and fully mixed on an oscillator and maintained at room temperature for 5-15 min for denaturation. An equal volume of chloroform was added and mixed thoroughly on the oscillator, and then maintained at room temperature for $15 \mathrm{~min}$. RNA was extracted by centrifugation for $15 \mathrm{~min}$ at $14,000 \mathrm{xg}$ at $4^{\circ} \mathrm{C}$.

Microarray analysis. An equal quantity of RNA was extracted from each AD group. Following thorough mixing, RNA was extracted according to above mentioned method for microRNA microarray detection. The results were compared with those of the normal group and the differential expression of microRNAs was determined using Array-Pro software version 4.0 (Xingyuan Biotechnology Co., Ltd., Shanghai, China).

Reverse transcription (RT). A Taqman microRNA reverse transcriptase kit (Applera Corporation, Norwalk, CT, USA) and microRNA-specific stem loop structure reverse transcription primer (Umibio Co., Ltd., Shanghai, China) were used for the microRNA RT reaction. The experiment was performed according to the manufacturer's protocol (Applied Biosystems; Thermo Fisher Scientific, Inc., Waltham, MA, USA). Partial adjustment was made and the total reaction volume was $15 \mu 1$.

Quantitative polymerase chain reaction ( $q P C R)$ analysis. The primer sequences were designed and U6 snRNA was set as the internal control. The primers were designed by adding $0.08 \mu \mathrm{l}$ of upstream primer $(20 \mu \mathrm{M}), 0.08 \mu \mathrm{l}$ of downstream primers $(20 \mu \mathrm{M}), 2 \mu \mathrm{l}$ of cDNA template and water to $10 \mu \mathrm{l}$ of 2X PCR Master mix (containing 2X Taq DNA polymerase (2.5 U/ $\mu 1,2 \mathrm{X}$ PCR buffer and $2 \mathrm{X}$ dNTP) to a total volume of $20 \mu \mathrm{l}$. The cycling program of the PCR reactions was one cycle probe duration, 40 cycles of duration at $95^{\circ} \mathrm{C}$ for $15 \mathrm{sec}$, annealing at $58^{\circ} \mathrm{C}$ for $20 \mathrm{sec}$, extension at $72^{\circ} \mathrm{C}$ for $15 \mathrm{sec}$ and one cycle of post-extension. qPCR analysis was used for the quantitative analysis of microRNA-222 for the 3 groups. The $2^{-\Delta \Delta C q}$ method (15) was used to calculate the expression levels of microRNA. The procedure was repeated 3 times for each sample.

Statistical analysis. All data were analyzed using SPSS version 19.0 (IBM Corp., Armonk, NY, USA). The results are expressed as the mean \pm standard deviation. Student's t-test was used for measurement of data, and the $\chi^{2}$ test was used for enumeration of data. Multivariate regression analysis was also performed. $\mathrm{P}<0.05$ was considered to indicate a statistically significant difference.

\section{Results}

General data. Of the patients involved in the present study, there were 30 patients in the mild AD group (11 men and 19 women; average age, $63.3 \pm 11.5$ years) and 30 patients in the moderate AD group (12 men and 18 women; average age, $64.5 \pm 9.7$ years). An additional 30 patients were included in the normal group

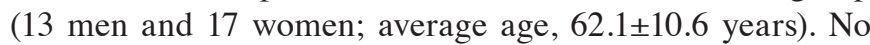
significant differences were identified in sex, age or medical history among the three groups ( $\mathrm{P}>0.05$; Table I).

Microarray detection. In the mild AD group, there were 35 sequences of microRNAs in which signal expression $>500 \mathrm{IU} / \mathrm{ml}$. The signal ratios of the differentially expressed microRNAs were clustered and divided into upregulation and downregulation groups. There were 27 strips in the upregulation group and 8 strips in the downregulation group (Fig. 1). In the moderate AD group, there were 34 sequences of microRNAs with signal expression $>500 \mathrm{IU} / \mathrm{ml}$. Among the 34 sequences of microRNAs, 23 were upregulated and 11 were downregulated (Fig. 2). There were 26 sequences with differential signal expression $>500 \mathrm{IU} / \mathrm{ml}$ in the mild and moderate groups, amongst which was microRNA-222. The expression of microRNA-222 was significantly decreased in the mild and moderate groups $(\mathrm{P}<0.05)$.

Results of RT-qPCR analysis of microRNA-222. RT-qPCR analysis was used to detect the expression levels of microRNA-222. The expression of microRNA-222 in the mild group was significantly decreased, compared with that in the normal group $(\mathrm{P}<0.05)$, which was consistent with the results 
Table I. Comparison of data three patient groups.

\begin{tabular}{|c|c|c|c|c|}
\hline Characteristic & $\begin{array}{c}\text { Normal } \\
(n=30)\end{array}$ & $\begin{array}{l}\text { Mild } \\
(n=30)\end{array}$ & $\begin{array}{c}\text { Moderate } \\
(\mathrm{n}=30)\end{array}$ & P-value \\
\hline Age (years) & $62.1 \pm 10.6$ & $63.3 \pm 11.5$ & $64.5 \pm 9.7$ & $\begin{array}{l}0.677^{\mathrm{a}} \\
0.435^{\mathrm{b}} \\
0.768^{\mathrm{c}}\end{array}$ \\
\hline Male (n, \%) & $13(43.3)$ & $11(36.7)$ & $12(40.0)$ & $\begin{array}{l}0.598^{\mathrm{a}} \\
0.793^{\mathrm{b}} \\
0.791^{\mathrm{c}}\end{array}$ \\
\hline Smoker (n, \%) & $11(36.7)$ & $8(26.7)$ & $9(30.0)$ & $\begin{array}{l}0.405^{\mathrm{a}} \\
0.584^{\mathrm{b}} \\
0.774^{\mathrm{c}}\end{array}$ \\
\hline Alcohol consumption $(\mathrm{n}, \%)$ & $12(40.0)$ & $9(30.0)$ & $8(26.7)$ & $\begin{array}{l}0.417^{\mathrm{a}} \\
0.273^{\mathrm{b}} \\
0.774^{\mathrm{c}}\end{array}$ \\
\hline Hypertension (n, \%) & $23(76.7)$ & $21(70.0)$ & $23(76.7)$ & $\begin{array}{l}0.559^{\mathrm{a}} \\
0.000^{\mathrm{b}} \\
0.559^{\mathrm{c}}\end{array}$ \\
\hline Diabetes $(\mathrm{n}, \%)$ & $7(23.3)$ & $5(16.7)$ & $8(26.7)$ & $\begin{array}{l}0.519^{\mathrm{a}} \\
0.766^{\mathrm{b}} \\
0.347^{\mathrm{c}}\end{array}$ \\
\hline $\mathrm{CHD}(\mathrm{n}, \%)$ & $3(10.0)$ & $2(6.7)$ & $4(13.3)$ & $\begin{array}{l}0.640^{\mathrm{a}} \\
0.688^{\mathrm{b}} \\
0.389^{\mathrm{c}}\end{array}$ \\
\hline HHcy $(\mathrm{n}, \%)$ & $6(20.0)$ & $7(23.3)$ & $5(16.7)$ & $\begin{array}{l}0.754^{a} \\
0.739^{b} \\
0.519^{c}\end{array}$ \\
\hline $\mathrm{Fg}(\mathrm{g} / \mathrm{l})$ & $3.0 \pm 1.14$ & $2.8 \pm 0.87$ & $2.9 \pm 0.93$ & $\begin{array}{l}0.446^{\mathrm{a}} \\
0.673^{\mathrm{b}} \\
0.395^{\mathrm{c}}\end{array}$ \\
\hline $\mathrm{CRP}(\mathrm{mmol} / \mathrm{l})$ & $3.9 \pm 4.22$ & $4.1 \pm 3.61$ & $3.5 \pm 6.61$ & $\begin{array}{l}0.487^{\mathrm{a}} \\
0.628^{\mathrm{b}} \\
0.309^{\mathrm{c}}\end{array}$ \\
\hline
\end{tabular}

Data for age, Fg and CRP are presented as the mean \pm standard deviation. ${ }^{\mathrm{a} C o m p a r i s o n}$ between normal and mild groups; ${ }^{\mathrm{b}}$ comparison between normal and moderate groups; ${ }^{c}$ comparison between mild and moderate groups. CHD, coronary heart disease; HHcy, homocysteine; Fg, fibrinogen; CRP, C-reactive protein.

of the microarray detection. The expression of microRNA-222 in the moderate group was significantly lower, compared with that in the normal group $(\mathrm{P}<0.05)$, which was also consistent with the results of the microarray analysis. In addition, the expression of microRNA-222 in the moderate group was significantly lower, compared with that in the mild group $(\mathrm{P}<0.05)$.

\section{Discussion}

Previous studies have shown that microRNAs are closely associated with the occurrence and development of tumors, cardiovascular disease, diabetes, human genetic diseases and nervous system diseases (16-19). Certain microRNAs are also important in neurodegenerative diseases (20), particularly in the occurrence and development of AD (21). MicroRNAs have been shown to regulate amyloid precursor protein (APP) in cell experiments and affect the deposition of amyloid $\beta(A \beta)(22,23)$. It has been shown that microRNAs have an effect on AD in a transgenic mouse model of AD (24). Sohonrook et al (25) reported that certain microRNAs promote the production of $\mathrm{A} \beta$, which can alter the expression of microRNAs and become an initiating factor in microRNA network imbalance. There is a complicated connection between microRNAs and $\mathrm{A} \beta$, which cause mutual promotion and can have effects on each other in vivo, and has an effect on the occurrence and development of $\mathrm{AD}$ (25). It has been demonstrated that microRNA-125b induces the hyperphosphorylation of tau protein (26). The mechanism involves the target inhibition of phosphatase DUSP6, and the PPPl CA-induced phosphorylation of protein (26). It has also been shown that miR-125b can cause damage in a combined experiment in mice (26). Therefore, 


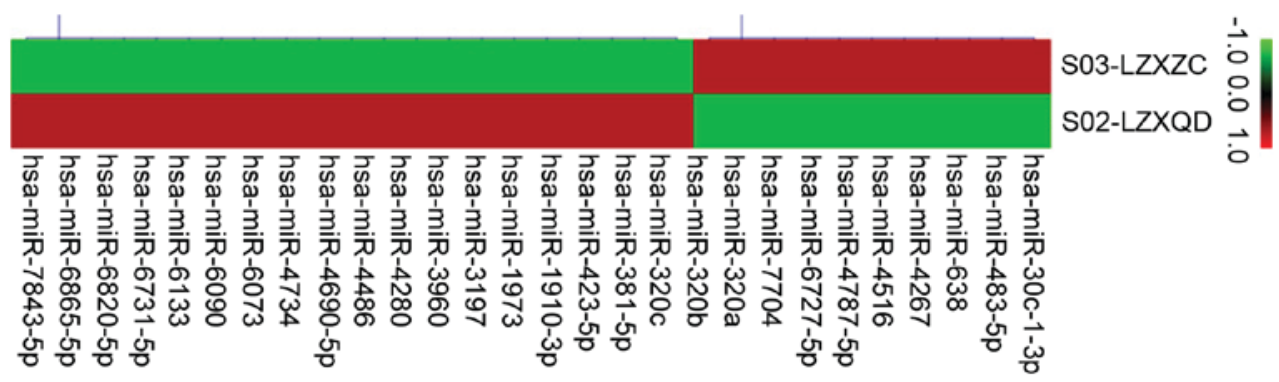

Figure 1. Differences in microRNA clustering between the mild Alzheimer's disease and normal groups. The green part of the figure indicates that the miRNA has a low expression level in the corresponding sample, and the red part indicates that the miRNA has a high level of expression in the corresponding sample. The first line is the normal group and the following line is the mild group. miR, microRNA.

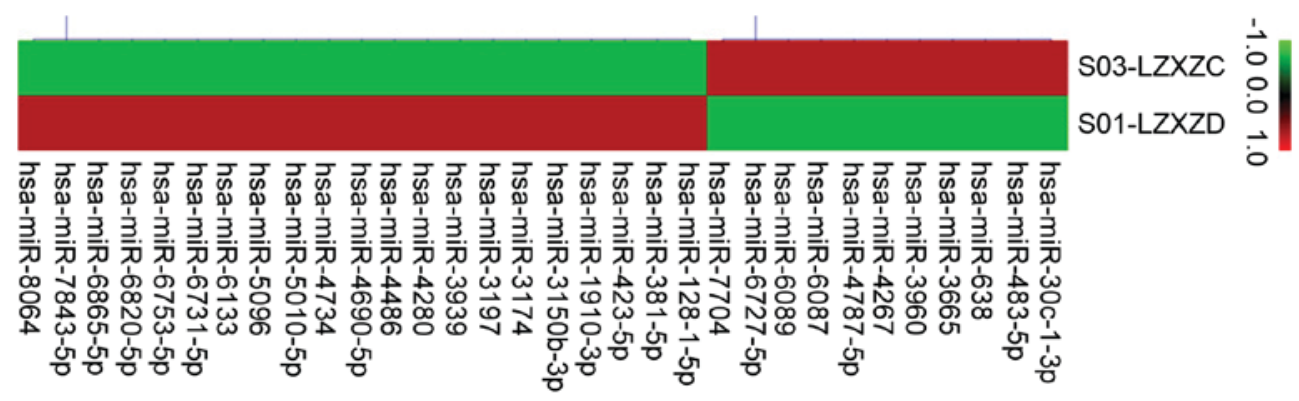

Figure 2. Expression of microRNA-222 and U6 as a reference gene. The first line is the normal group and the following line is the moderate group. miR, microRNA.

microRNAs are involved in the occurrence of AD based on a variety of mechanisms.

Investigations of microRNAs in patients with AD remain limited. In the present study, the serum levels of microRNAs in patients with $\mathrm{AD}$ and normal patients were detected using biological chip technology. The results showed that there were significant differences in microRNA expression levels. In the mild $\mathrm{AD}$ group, 35 strips were identified with a signal difference of $>500 \mathrm{IU} / \mathrm{ml}$, whereas in the moderate group, 34 strips were identified, with 26 strips containing the same microRNAs. MicroRNAs with differences have been previously reported (22-24), which require further investigations in relation to the occurrence and development of $\mathrm{AD}$.

The results of the RT-qPCR analysis showed that microRNA-222 was significantly decreased in the mild and moderate AD groups $(\mathrm{P}<0.05)$, which was consistent with the results of the microarray analysis and indicated that the downregulation of microRNA-222 may have induced the occurrence of $\mathrm{AD}$. It is known that $\mathrm{P} 27 \mathrm{kipl}$ is a cell cycle-dependent kinase inhibitor, which is involved in the occurrence and development of $\mathrm{AD}$ (27). Wang et al (28) compared mice in an AD model with the age-matched normal mice, and found that the expression of microRNA-222 in the AD mice was downregulated, which was associated with an increase in the protein expression of p27kip1. Wang et al (28) demonstrated that microRNA-222 is involved in the pathogenesis of $\mathrm{AD}$ by affecting cell cycle dysfunction and the expression of p27kip1. Zhang et al (29) reported that, in samples with high expression levels of microRNA-222, low expression levels of p53 upregulated modulator of apoptosis (PUMA) were found in $81 \%$ of samples $(\mathrm{P}<0.001)$. In samples with downregulated expression of microRNA-222, a high expression level of PUMA was found in $79 \%$ of the samples. PUMA is a novel member of the B-cell lymphoma 2 (Bcl-2) family identified by Yu et al (30) in 2001. UMA- $\alpha$ and PUMA- $\beta$ contain a BH3 domain and have been widely investigated; UMA- $\alpha$ and PUMA- $\beta$ are important in the interaction between PUMA protein, other members of the Bcl-2 family and neuronal apoptosis (30). Regulation of the gene expression of Bcl-2 may be involved in the pathogenesis of $\mathrm{AD}$ (31). It has been shown that PUMA induces apoptosis through p53-dependent and -independent apoptotic pathways. These pathways ultimately induce the release of apoptotic signaling factors, including cytochrome $c$, through alterations in mitochondrial membrane potential. The activation of caspase- 3 and -9 further mediates the apoptosis of cells, and the increased expression of caspase-3 and -9 induces the occurrence of AD. Ok and Martin (32) confirmed that APP cutting products are mediated by caspase- 3 , and A $\beta$ is co-localized in $\mathrm{AD}$ senile plaques. Caspase-3 is important in regulating the production of $A \beta$ with neurotoxicity and in the final apoptosis of AD neurons (28). MicroRNA-222 is involved in the pathogenesis of $\mathrm{AD}$ and the level of microRNA-222 in the hippocampus is higher, compared with that in other regions (33). In the present study, the results of the RT-qPCR analysis also revealed that serum microRNA-222 in the moderate AD group was significantly decreased, compared with the mild $\mathrm{AD}$ group $(\mathrm{P}<0.05)$, which, to the best of our knowledge, has not been 
reported previously. With the progression of $\mathrm{AD}$, the expression of serum microRNA-222 was decreased in patients; however, further confirmation is required.

In conclusion, serum levels of microRNA-222 can indirectly reflect alterations in the expression of microRNA-222 in brain tissues; however, the mechanism underlying the decrease in its expression in serum of patients with $\mathrm{AD}$ warrants further investigation. The expression of microRNA-222 in patients with AD was significantly decreased, and this maybe a potential biomarker for the diagnosis of AD or serve as a therapeutic target.

\section{Acknowledgements}

This study was supported by Fund of Science and Technology Bureau of Lianyungang (grant no. SH1224).

\section{References}

1. Ballard C, Gauthier S, Corbett A, Brayne C, Aarsl D and Jones E: Alzheimer's disease. Lancet 377: 1019-1031, 2011.

2. Blennow K, de Leon MJ and Zetterberg H: Alzheimer's disease. Lancet 368: 387-403, 2006.

3. Taki T: An approach to glycobiology from glycolipidomics: Ganglioside molecular scanning in the brains of patients with Alzheimer's disease by TLC-blot/matrix assisted laser desorption/ionization-time of flight MS. Biol Pharm Bull 35: 1642-1647, 2012.

4. Yang MH, Yang YH, Lu CY, Jong SB, Chen LJ, Lin YF, Wu SJ, Chu PY, Chung TW and Tyan YC: Activity-dependent neuroprotector homeobox protein: A candidate protein identified in serum as diagnostic biomarker for Alzheimer's disease. J Proteomics 75: 3617-3629, 2012.

5. Hu ZP, Browne ER, Liu T, Angel TE, Ho PC and Chan CY: Metabonomic profiling of TASTPM transgenie Alzheimer's disease mouse model. J Proteome Res 11: 5903-5913, 2012.

6. Han X, Rozen S, Boyle SH, Hellegers C, Cheng H, Burke JR, Welsh-Bohmer KA, Doraiswamy PM and Kaddurah-Daouk R: Metabolomics in early Alzheimer's disease: Identification of altered plasma sphingolipidome using shotgun lipidomits. PLoS One 6: e21643, 2011.

7. Krol J, Loedige I and Filipowicz W: The widespread regulation of microRNA biogenesis, function and decay. Nat Rev Genet 11: 597-610, 2010.

8. Harfe BD: MicroRNAs in vertebrate development. Curr Opin Genet Dev 15: 410-415, 2005.

9. Cohen JE, Lee PR, Chen S, Li W and Fields RD: MicroRNA regulation of homeostatic synaptic plasticity. Proc Natl Acad Sci USA 108: 11650-11655, 2011.

10. Gao J, Wang WY, Mao YW, Gräff J, Guan JS, Pan L, Mak G, Kim D, Su SC and Tsai LH: A novel pathway regulates memory and plasticity via SIRT1 and miR-134. Nature 466: 1105-1109, 2010.

11. Krichevsky AM, King KS, Donahue CP, Khrapko K and Kosik KS: A microRNA array reveals extensive regulation of microRNAs during brain development. RNA 9: 1274-1281,2003.

12. Resnick KE, Alder H, Hagan JP, Richardson DL, Croce CM and Cohn DE: The detection of differentially expressed microRNAs from the serum of ovarian cancer patients using a novel real-time PCR platform. Gynecol Oncol 112: 55-59, 2009.

13. McKhann GM, Knopman DS, Chertkow H, Hyman BT, Jack CR Jr, Kawas CH, Klunk WE, Koroshetz WJ, Manly JJ, Mayeux R, et al: The diagnosis of dementia due to Alzheimer's disease: Recommendations from the National Institute on Aging-Alzheimer's Association workgroups on diagnostic guidelines for Alzheimer's disease. Alzheimers Dement 7: 263-269, 2011.
14. Folstein MF, Folstein SE and Mchugh PR: 'Mini-mental state': A practical method for grading the cognitive state of patients for the clinician. J Psychiatr Res 12: 189-198, 1975.

15. Livak KJ and Schmittgen TD: Analysis of relative gene expression data using real-time quantitative PCR and the 2(-Delta Delta C(T)) method. Methods 25: 402-408, 2001.

16. Li M,Li BY,Xia H and Jiang LL: Expression of microRNA-142-3p in cervical cancer and its correlation with prognosis. Eur Rev Med Pharnacol Sci 21: 2346-2350, 2017.

17. Jin $\mathrm{P}, \mathrm{Gu} \mathrm{W}$, Lai Y, Zheng W, Zhou Q and Wu X: The circulating microRNA-206 level predicts the severity of pulmonary hypertension in patients with left heart diseases. Cell Physiol Biochem 41: 2150-2160, 2017.

18. Zou HL, Wang Y, Gang Q, Zhang Y and Sun Y: Palsma level of miR-93 is associated with higher risk to develop type 2 diabetic retinopathy. Graefes Arch Clin Exp Ophthalmol 255: 1159-1166, 2017.

19. Yu X, Li Z, Shen J, Chan MT and Wu WK: Role of microRNAs in primary central nervous system lymphomas. Cell Prolif 49: $147-153,2016$.

20. Junn E and Mouradian MM: MicroRNAs in neurodegenemtive diseases and their therapeutic potential. Pharmacol Ther 133: 142-150, 2012.

21. Wong HK, Veremeyko T, Patel N, Lemere CA, Walsh DM, Esau C, Vanderburg C and Krichevsky AM: De-repression of FOX03a death axis by microRNA-132 and-212 causes neuronal apoptosis in Alzheimer's disease. Hum Mol Genet 22: 3077-3092, 2013.

22. Long JM, Ray B and Lahiri DK: MicroRNA-153 physiologically inhibits expression of amyloid- $\beta$ precursor protein in cultured human fetal brain cells and is dysregulated in a subset of Alzheimer disease patients. J Biol Chem 287: 31298-31310, 2012.

23. Fang M, Wang J, Zhang X, Geng Y, Hu Z, Rudd JA, Ling S, Chen $\mathrm{W}$ and Han $\mathrm{S}$ : The miR-124 regulates the expression of BACE1 $/ \beta$-secretase correlated with cell death in Alzheimer's disease. Toxicol Lett 209: 94-105, 2012.

24. Hébert SS, Horré K, Nicolaï L, Bergmans B, Papadopoulou AS, Delacourte A and De Strooper B: MicroRNA regulation of Alzheimer's amyloid precursor protein expression. Neurobiol Dis 33: 422-428, 2009.

25. Sohonrook N, Ke YD, Humphreys D, Staufenbiel M, Ittner LM, Preiss T and Götz J: Neuronal mircoRNA deregulation in response to Alzheimer's disease amyloid-beta. PLoS One 5: e11070, 2010.

26. Banzhaf-Strathmann J, Benito E, May S, ArzbergerT, Tahirovic S, Kretzschmar H, Fischer A and Edbauer D: MicroRNA-125b induces tau hyperphosphorylation and cognitive deficits in Alzheimer's disease. EMBO J 33: 1667-1680, 2014.

27. Ogawa O, Lee HG, Zhu X, Raina A, Harris PL, Castellani RJ, Perry G and Smith MA: Increased p27, an essential component of cell cycle control, in Alzheimer's disease. Aging Cell 2: 105-110, 2003.

28. Wang X, Xu Y, Zhu H, Ma C, Dai X and Qin C: Downregulated microRNA-222 is correlated with increased $\mathrm{p} 27^{\mathrm{Kip} 1}$ expression in a double transgenic mouse model of Alzheimer's disease. Mol Med Rep 12: 7687-7692, 2015.

29. Zhang CZ, Zhang JX, Zhang AL, Shi ZD, Han L, Jia ZF, Yang WD, Wang GX, Jiang T, You YP, et al: Mir-221 and miR-222 target PUMA to induce cell survival in glioblastoma. Mol Cancer 9: 229, 2010.

30. Yu J, Zhang L, Hwang PM, Kinzler KW and Vogelstein B: PUMA induces the rapid apoptosis of colorectal cancer cells. Mol Cell 7: 673-682, 2001.

31. Shibata M, Murray M, Tessler A, Ljubetic C, Connors T and Saavedra RA: Single injections of a DNA plasmid that contains the human Bcl-2 gene prevent loss and atrophy of distinct neuronal populations after spinal cord injury in adult rats. Neurorehabil Neural Repair 14: 319-330, 2000.

32. Lok J and Martin LJ: Rapid subcellular redistribution of Bax precdes caspase-3 and endonuclease activation during excitoxic neuronal apoptosis in rat brain. J Neurotrauma 19: 815-828, 2002.

33. Feng W and Feng Y: MicroRNAs in neural cell development and brain diseases. Sci China Life Sci 54: 1103-1112, 2011. 